\title{
RH NEGATIVE PREGNANCY: MATERNAL AND PERINATAL OUTCOME IN BUNDELKHAND REGION
}

\author{
Sippy Agarwal ${ }^{1}$, Seema ${ }^{2}$, Sanjaya Sharma ${ }^{3}$, Vidya Chaudhary4, Shashi Bala ${ }^{5}$, Umesh $^{6}$
}

${ }^{1}$ Assistant Professor, Department of OBG, MLB Medical College, Jhansi.

${ }^{2} 3^{\text {rd }}$ Year Junior Resident, Department of OBG, MLB Medical College, Jhansi.

3 Professor and HOD, Department of OBG, MLB Medical College, Jhansi.

${ }_{4}^{4}$ Associate Professor, Department of OBG, MLB Medical College, Jhansi.

${ }_{53}^{\text {rd }}$ Year Junior Resident, Department of OBG, MLB Medical College, Jhansi.

${ }^{6} 2^{\text {nd }}$ Year Junior Resident, Department of OBG, MLB Medical College, Jhansi.

\begin{tabular}{l} 
ABSTRACT \\
\hline Incidence of Rh negative pregnancy in Western countries is $15 \%$, but in India it varies from 3\% to $5.7 \%$. It is a high risk pregnancy, \\
as it may cause antigen-antibody reaction and haemolysis. It can lead to perinatal loss of 1 to $2.5 \%$.
\end{tabular}

\section{AIMS AND OBJECTIVE}

To assess maternal and perinatal outcome among $\mathrm{Rh}$ negative pregnancies.

\section{MATERIAL AND METHODS}

It was an observational study conducted in Department of Obstetrics and Gynaecology in Maharani Laxmi Bai Medical College, Jhansi from November 2013 to October 2015. In this study, we have observed the maternal outcome in the form of gravidity and mode of delivery and perinatal outcome in the form of gestational age, NICU admission, IUD and NND.

\section{RESULTS}

In the present study among 125 patients, $52.8 \%$ patients were vaginally delivered and $47.2 \%$ were delivered through LSCS. Among 125 patients $14.4 \%$ were early preterm birth, $19.2 \%$ were late preterm birth, $59.2 \%$ were term birth and $2.4 \%$ were post term birth. Perinatal outcome in 125 patients was $89.6 \%$ were healthy, NICU admission were 4.8\%, IUD were $3.2 \%$ and $2.4 \%$ were NND. The conventional treatment measures are appropriate hydration, phototherapy and exchange transfusion.

\section{CONCLUSION}

$\mathrm{Rh}$ haemolytic disease of the new-born forms common and preventable cause of maternal and perinatal morbidity. Anti-D IgG administration and proper fetal and neonatal monitoring when required decreases the burden of disease.

\section{KEYWORDS}

Rhesus Isoimmunisation, Anti-D, Rh-Negative Women.

HOW TO CITE THIS ARTICLE: Agarwal S, Seema, Sharma S, et al. Rh negative pregnancy: maternal and perinatal outcome in Bundelkhand region. J. Evolution Med. Dent. Sci. 2016;5(71):5165-5168, DOI: 10.14260/jemds/2016/1171

\section{INTRODUCTION}

Rhesus antigen was $1^{\text {st }}$ discovered in rhesus monkey. "Rhesus antigen" was named after monkey Macacus rhesus with whom about $85 \%$ human being shares this red cell antigen. ${ }^{1}$ Incidence of $\mathrm{Rh}$ negative pregnancy in Western countries is $15 \%$, but in India it varies from $5 \%$ to $8 \% .^{2}$ It is a high risk pregnancy, as it may cause antigen-antibody reaction and haemolysis. It can lead to perinatal loss of 1 to $2.5 \% .^{3}$ The genetic locus for the Rh antigen complex is on the short arm of chromosome 1.

According to presence and absence of antigen, it is called rhesus positive and rhesus negative. If a pregnant women and her husband is rhesus negative, no incompatibility is there. If her husband is positive, the baby will inherit the father's blood group, creating incompatibility between mother and her foetus. If genotype of the husband is homozygous, all the babies will be affected by haemolytic disease and if

Financial or Other, Competing Interest: None.

Submission 20-07-2016, Peer Review 20-08-2016,

Acceptance 26-08-2016, Published 03-09-2016.

Corresponding Author:

Dr. Seema,

D/o Sh. Hazari Lal,

VPO Dhigawa Mandi, Tehsil Loharu,

Bhiwani-127201, Haryana.

E-mail: seema.gynae@gmail.com

DOI: $10.14260 /$ jemds/2016/1171 heterozygous $50 \%$ of babies will be affected. It follows Mendelian dominant inheritance. So investigation of blood for $\mathrm{Rh}$ and $\mathrm{ABO}$ grouping becomes almost a routine during the first antenatal visit in first trimester. If the woman is found $\mathrm{Rh}-$ negative, Rh grouping of the husband is to be done to find out whether the pregnancy is a result of incompatible or compatible mating. If the husband is also Rh-negative, i.e. compatible mating, there is no problem so far as Rh factor is concerned. Whenever there is fetomaternal haemorrhage, there is formation of IgM antibody in maternal blood for short period followed by production of IgG. These antibodies could pass back to placenta and harm the developing baby's red blood cells causing haemolysis. Excessive removal of circulatory red blood cell leads to severe anaemia and hypoxia. Erythropoiesis results in hepatosplenomegaly. Tissue hypoxia and hypoproteinaemia results in cardiac and circulatory failure with generalised oedema and hydrops. Rh disease accounts for $97 \%$ of Haemolytic Disease of the New-born (HDN), remaining $3 \%$ is caused by isoimmunisation against other fetal antigenic groups such as Kell, non-D Rh, Duffy, Kidd and MNS. ${ }^{4}$ The rate of isoimmunisation increase with quantum of fetomaternal leak. FMH measurements following potentially sensitising events is also necessary. It can be done by acid elution method, Kleihauer-Betke (KB) test, and flow cytometric measurement. Affection of the mother: The impact 
of Rh incompatibility mainly falls on the baby. The mother may also be affected somewhat. There is increased incidence of: (1) Pre-eclampsia; (2) Polyhydramnios; (3) Big size baby with its hazards; (4) Hypofibrinogenemia due to prolonged retention of dead fetus in uterus; (5) Postpartum haemorrhage due to big placenta and blood coagulopathy; (6) 'Maternal syndrome'-The salient features are generalised oedema, proteinuria and pruritus due to cholestasis. These features are ominous indicating imminent fetal death in utero. In all cases of Rh-negative women irrespective of blood grouping and parity, IgG antibody is detected by indirect Coombs' test.

- If the test is found negative at 12 th week, it is to be repeated at 28th and 36th week in primigravida. In multigravida, the test is to be repeated at monthly intervals from 24 weeks onwards.

- If the test is found positive: The patient should be supervised in centres equipped to tackle with Rh problem (Specialised fetal medicine unit).

- Genotype of the husband is to be determined. If he is found to be homozygous, the fetus is likely to be affected and in heterozygous the fetus may be affected in $50 \%$ cases. In that case, fetal blood group is determined (see below). If the fetus is found to be Rh(D) negative, no further tests are required and routine care is continued.

- Fetal Rh Status: Amniotic fluid or Chorionic Villi (CVS). Uncultured amniocytes or trophoblasts.

- $\quad$ PCR for fetal DNA testing to detect fetal blood group. Fetal DNA, present in maternal plasma can be genotyped. This method has replaced amniocentesis, which is an invasive method.

- Quantitative estimation of IgG antibody at weekly intervals. Sudden marked rise in the titre from 1:8 to $1: 256$ is very much suggestive of fetal affection. Some centres consider the titer of $1: 16$ or antibody level $>10$ $\mathrm{IU} / \mathrm{mL}$ as a critical one. One should make a cautious interpretation of the rise or fall in the titer. Fetal affection in utero is identified by evaluating optical density of amniotic fluid, serial ultrasonography for detecting fetal ascites, pericardial and pleural effusion, scalp oedema and hepatosplenomegaly and middle cerebral artery peak systolic velocity. In mild affection, the pregnancy may be continued up to 38 weeks and then termination is to be done.

In severe affection: It is reasonable to terminate the pregnancy around 34 weeks after maternal steroid administration. In every case of premature termination before 34 weeks, it is desirable to confirm the fetal lung maturation by measuring the L:S ratio in the amniotic fluid. In a specialised centre where there is severe affection before 34 weeks, intrauterine fetal transfusion (Intraperitoneal or intravascular) is done to continue pregnancy beyond 34 weeks. Rh incompatibility is almost completely preventable. Rh-negative mothers should be followed closely by their providers during pregnancy. Overall, $16 \%$ of $\mathrm{Rh}$ negative pregnancies are at risk of isoimmunisation and risk is reduced to 1.5 to $2.0 \%$ with immunoprophylaxis with injection anti-D antenatally at $28^{\text {th }}$ week of gestation. ${ }^{5}$ These injections prevent the development of antibodies against Rh-positive blood. However, women with Rh-negative blood type must get injections: During every pregnancy after a miscarriage or abortion, after prenatal tests such as amniocentesis and chorionic villus biopsy, cordocentesis, antepartum haemorrhage, external cephalic version, intrauterine death and stillbirth, in utero therapeutic interventions, after injury to the abdomen during pregnancy. Anti D-gamma globulin is administered intramuscularly to the mother $300 \mu \mathrm{g}$ following delivery. All Rh-negative unsensitised women should receive $50 \mu \mathrm{g}$ of Rh-immune globulin IM within 72 hours of induced or spontaneous abortion, ectopic or molar pregnancy or CVS in the first trimester. Women with pregnancy beyond 12 weeks should have full dose of $300 \mu \mathrm{g}$. Generally, $300 \mu \mathrm{g}$ dose will protect a woman from fetal haemorrhage of up to $30 \mathrm{~mL}$ of fetal whole blood. Mode of action is Antibody-Mediated Immune Suppression (AMIS). The possible mechanisms are: (i) The anti-D antibody when injected blocks the Rh-antigen of the fetal cells; (ii) The intact antibody coated fetal red cells are removed from the maternal circulation by the spleen or lymph nodes; (iii) Central inhibition - the fetal red cells, coated with anti-D antibodies interfere the production of IgG from the B cells. In this way, maternal and perinatal outcome can improve. Exchange transfusion is a life-saving procedure in severely affected haemolytic disease of the new-born. Exchange transfusion is a life-saving procedure in severely affected haemolytic disease of the new-born. Adjuvant therapy: Phototherapy is to be continued for 24 hours. Phototherapy (Blue or blue green light of 420-470 nm wave length) degrades bilirubin by photo-oxidation and structural isomerisation and photochemical reactions convert bilirubin to less toxic and water soluble polar isomer or to lumirubin. Phenobarbitone, $3-5 \mathrm{mg} / \mathrm{kg}$ body weight is to be administered thrice daily intramuscularly. Phenobarbitone increases the glucuronyl transferase enzyme activity in the fetal and neonatal liver to conjugate the bilirubin, which hastens its clearance. Antibiotics should be administered for 3-5 days.

\section{MATERIAL AND METHODS}

This was a prospective observational study conducted in all $\mathrm{Rh}$ negative pregnant women who presented in outdoor and emergency department of Department of Obstetrics and Gynaecology in Maharani Laxmi Bai Medical College, Jhansi from Nov. 2013 to Oct. 2015. All pregnant women with Rh negative blood group irrespective to their age, parity, gestational age and administration of $\mathrm{Rh}$ anti-D Ig in previous or present pregnancy were included in the study. A proper history of patients was taken, general and obstetrical examination was done and all the routine antenatal investigations along with indirect Coombs' test were sent. Maternal outcome in form of gravidity and mode of delivery and perinatal outcome in form of gestational age, NICU admission, IUD and NND.

\section{RESULTS}

In present study, 125 rhesus negative antigen pregnant women were studied. Among all $38.4 \%$ were primigravida, $33.6 \%$ were second gravid, $20 \%$ were third gravid and $8 \%$ were multigravida.

\begin{tabular}{|c|c|c|}
\hline Parity & No. of Patients & $\mathbf{\%}$ \\
\hline Primigravida & 48 & $38.4 \%$ \\
\hline Second Gravida & 42 & $33.6 \%$ \\
\hline Third Gravida & 25 & $20 \%$ \\
\hline Multigravida & 10 & $8 \%$ \\
\hline
\end{tabular}

Table 1: Distribution of Parity among Rh Negative Pregnant Patients 
Among 125 patients $34.4 \%$ belonged to $18-22$ years, $42.2 \%$ belonged to $23-26$ years, $18.4 \%$ belonged to $27-30$ years and $7.2 \%$ belonged to $>30$ years of age.

\begin{tabular}{|c|c|c|}
\hline Age Group (Years) & No. of Patients & \% \\
\hline $18-22$ & 43 & $34.4 \%$ \\
\hline $23-26$ & 53 & $42.4 \%$ \\
\hline $27-30$ & 23 & $18.4 \%$ \\
\hline$>30$ & 9 & $7.2 \%$ \\
\hline \multicolumn{2}{|c|}{ Table 2: Age Distribution among Rh } \\
\hline \multicolumn{2}{|c|}{ Negative Pregnant Patients } \\
\hline
\end{tabular}

Among 125 patients, $14.4 \%$ were early preterm birth, $19.2 \%$ were late preterm birth, $59.2 \%$ were term birth and $2.4 \%$ were post term birth.

\begin{tabular}{|c|c|c|}
\hline $\begin{array}{c}\text { Gestational Age } \\
\text { at Delivery }\end{array}$ & $\begin{array}{c}\text { No. of } \\
\text { Patients }\end{array}$ & $\mathbf{\%}$ \\
\hline$<34$ weeks & 18 & $14.4 \%$ \\
\hline $34-37$ weeks & 24 & $19.2 \%$ \\
\hline $37-42$ weeks & 74 & $59.2 \%$ \\
\hline$>42$ weeks & 3 & $2.4 \%$ \\
\hline $\begin{array}{c}\text { Table 3: Gestational Age at Delivery among } \\
\text { Rh Negative Pregnant Patients }\end{array}$ \\
\hline
\end{tabular}

Among 125 patients, $52.8 \%$ patients were vaginally delivered and $47.2 \%$ were delivered through LSCS.

\begin{tabular}{|c|c|c|}
\hline Method of Delivery & No. of Patients & $\%$ \\
\hline Vaginal Delivery & 66 & $52.8 \%$ \\
\hline $\begin{array}{l}\text { Operative Vaginal Delivery } \\
\text { (Forceps/Ventouse) }\end{array}$ & 0 & $0 \%$ \\
\hline LSCS & 59 & $47.2 \%$ \\
\hline \multicolumn{3}{|c|}{$\begin{array}{l}\text { Table 4: Method of Delivery among } \\
\text { Rh Negative Pregnant Patients }\end{array}$} \\
\hline
\end{tabular}

Among 125 patients $15.2 \%$ were A negative, $48 \%$ were $B$ negative, $7.2 \%$ were $A B$ negative and $29.6 \%$ were 0 negative.

\begin{tabular}{|c|c|c|}
\hline Blood Group & No. of Patients & $\mathbf{\%}$ \\
\hline A Negative & 19 & $15.2 \%$ \\
\hline B Negative & 60 & $48 \%$ \\
\hline AB Negative & 9 & $7.2 \%$ \\
\hline O Negative & 37 & $29.6 \%$ \\
\hline \multicolumn{2}{|c|}{ Table 5: Blood Group Distribution among } \\
Rh Negative Pregnant Patients \\
\hline
\end{tabular}

Perinatal outcome in 125 patients was $89.6 \%$ were healthy, NICU admission were $4.8 \%$, IUD were $3.2 \%$ and $2.4 \%$ were NND.

\begin{tabular}{|c|c|c|}
\hline Perinatal Outcome & No. of Patients & $\mathbf{\%}$ \\
\hline Healthy Baby & 112 & $89.6 \%$ \\
\hline NICU Admission & 6 & $4.8 \%$ \\
\hline IUD & 4 & $3.2 \%$ \\
\hline NND & 3 & $2.4 \%$ \\
\hline \multicolumn{2}{|c|}{ Table 6: Perinatal Outcome among Negative Pregnancy Patients } \\
\hline
\end{tabular}

\section{DISCUSSION}

Rhesus isoimmunisation causing fetal anaemia, neonatal hyperbilirubinaemia, hydrops fetalis is a problem in India. It is a preventable disease. There are two prophylaxis, one is antenatal anti-D prophylaxis and second is post-natal anti-D prophylaxis. Joseph from CMC Vellore used decision analysis technique in the year 2000 and found that there was gross underutilisation of anti-D prophylaxis in India. ${ }^{6}$ Deka et al observed that failure to administer post-natal anti-D prophylaxis was responsible for Rh-D alloimmunisation in more than $50 \%$ cases followed by failure to administer anti-D after Medical Termination of Pregnancy (MTP) (10\%). ${ }^{5}$ Fogsi recommends a single dose of 300 mcg at 28 weeks followed by post-natal prophylaxis by $300 \mathrm{mcg}$ as soon as possible if the baby in Rh positive and DCT is negative and $100 \mathrm{mcg}$ anti-D after the sensitising event of the first trimester. This postpartum anti-D dose is sufficient enough to neutralise $30 \mathrm{~mL}$ of fetal blood. The present study was undertaken to show the burden of HDN due to $\mathrm{Rh}$ incompatibility, which is a preventable condition and illuminates various causes for the persistence of this.

In the present study, $34.4 \%$ belonged to age group $18-22$ years followed by $42.2 \%$ in $23-26$ years' age group. This scenario was most probably due to early marriage and early childbearing among the Indian population. In present study, 125 rhesus negative antigen pregnant women were studied. Among all $38.4 \%$ were primigravida, $33.6 \%$ were second gravida, $20 \%$ were third gravida and $8 \%$ were multigravida.

Among 125 patients, $52.8 \%$ patients were vaginally delivered and $47.2 \%$ were delivered through LSCS.

Among 125 patients, $14.4 \%$ were early preterm birth, $19.2 \%$ were late preterm birth, $59.2 \%$ were term birth and $2.4 \%$ were post term birth.

Perinatal outcome in 125 patients was $89.6 \%$ were healthy, NICU admission were $4.8 \%$, IUD were $3.2 \%$ and $2.4 \%$ were NND. The conventional treatment measures are appropriate hydration, phototherapy and exchange transfusion. According to Nardozza LM et al, perinatal mortality was significantly higher in the $99 \mathrm{Rh}$-negative isoimmunised patients than in the 192 unimmunised patients (12.1\% versus $1 \%, \mathrm{p}=0.0001) .^{7}$

\section{CONCLUSION}

Rhesus isoimmunisation is a preventable cause of fetal morbidity and mortality. All pregnant women as soon as pregnancy is diagnosed should be checked for blood group. If blood group is negative, husband's blood grouping should be done. If positive, indirect Coombs' test should be done to diagnose antibody titre. Recommended antenatal and postnatal prophylaxis should be taken to prevent isoimmunisation. As per Moise $\mathrm{KJ} \mathrm{Jr}$ et al, Rhesus immune globulin has decreased the prevalence of rhesus D alloimmunisation in pregnancy so that only approximately six cases occur in every 1,000 live births. ${ }^{8}$ In utero fetal transfusion can also be helpful in decreasing the severity of disease in fetuses. According to Pasman SA et al, in experienced hands IUT for RBC-alloimmunisation is a safe procedure in this era. Patients should be referred to specialist centres prior to the development of hydrops. IUT in a free loop of cord and unnecessary preterm birth are best avoided. ${ }^{9}$ After delivery baby's blood group, haemoglobin, DCT, S. bilirubin and reticulocyte counts should be done to monitor baby 
postnatally. So that baby can get early treatment for raised S. bilirubin. With all these measures, we can decrease the burden of disease in India. In India, the high cost of immunoglobulins and lack of supply by Government of India amounts for significant risk of isoimmunisation. Family planning should also be encouraged for immunised women, since the severity of haemolytic disease increases with increasing parity.

\section{REFERENCES}

1. Joseph KS, Kramer MS. The decline in Rh hemolytic disease: should Rh prophylaxis get all the credit? Am J Public Health 1998;88(2):209-15.

2. Kausar R. Pregnancy in the Rh-negative woman. Ind J for the Practising Doctor 2005;1(4):39-40.

3. Walvekar V, Anjaria PH. Historical aspects of rhesus isoimmunization. In: Shah D, Salvi V, eds. The rhesus factor, current concepts. $1^{\text {st }}$ edn. New Delhi: Jaypee Brothers, FOGSI Publication 2004:1-6.
4. Wiener AS, Peters HR. Hemolytic reactions following transfusions of blood of homologous group, with three cases in which the same agglutinogen was responsible. Ann Intern Med 1940;13(12):2306-22.

5. Schmidt PJ, Morrison EG, Shohl J. The antigenicity of the Rh-o (Du) blood factor. Blood 1962;20(2):196-202.

6. Makroo RN. The Rh blood group system. Compendium of transfusion medicine. $1^{\text {st }}$ edn. New Delhi: J Mitra \& Co Ltd 1999:45-8.

7. Nardozza LM, Camano L, Moron AF, et al. Perinatal mortality in $\mathrm{Rh}$ alloimmunized patients. Eur J Obstet Gynecol Reprod Biol 2007;132(2):159-62.

8. Moise KJ. Management of rhesus alloimmunization in pregnancy. Obstet Gynecol 2008;112(1):164-76.

9. Pasman SA, Claes L, Lewi L, et al. Intrauterine transfusion for fetal anemia due to red blood cell alloimmunization: 14 years experience in Leuven. Facts Views Vis Obgyn 2015;7(2):129-36. 